\title{
Analisis Pendapatan Usahatani Kakao \\ Di Kabupaten Pidie Jaya \\ Provinsi Aceh
}

\author{
Analysis of Cacao Farming Income \\ In Pidie Jaya District \\ Of Aceh Province
}

\author{
Rita Ariani \\ Program Studi Agribisnis Fakultas Pertanian Universitas Malikussaleh \\ Kampus Cot Teungku Nie, Reuleut, Muara Batu Aceh Utara 24355, Indonesia \\ Email: agrium.fpunimal@yahoo.co.id
}

Diterima 15 Agustus 2014; Dipublikasi 1 September 2014

\begin{abstract}
Abstrak
Penelitian ini bertujuan untuk: (1) menghitung besarnya pendapatan usahatani kakao, dan (2) menganalisis pendapatan usahatani kakao di Kabupaten Pidie Jaya Provinsi Aceh. Penelitian ini dilakukan dengan metode survey. Lokasi penelitian ditentukan dengan cara sengaja (purposive) yaitu Kabupaten Pidie Jaya. Lokasi penelitian meliputi 7 (tujuh) kecamatan, yaitu Bandar Baru, Bandar Dua, Trienggadeng, Meureudu, Meurah Dua, Ulim, dan Panteraja. Pemilihan lokasi dilakukan atas dasar bahwa masing-masing kecamatan tersebut merupakan daerah penghasil komoditi kakao. Populasi pada penelitian ini adalah semua petani kakao yang ada di Kabupaten Pidie Jaya Provinsi Aceh. Pengambilan sampel petani dilakukan dengan metode simple random sampling yakni pengambilan secara acak sederhana. Jumlah sampel dalam penelitian ini sebanyak 101 responden yang berasal dari lokasi keseluruhan kecamatan yang ada di Kabupaten Pidie Jaya. Hasil penelitian diperoleh bahwa pendapatan usahatani kakao per hektar per kecamatan di Kabupaten Pidie Jaya sebesar Rp 14.400.000,-. Analisis pendapatan usahatani kakao ditunjukkan oleh nilai R/C ratio sebesar 1,66 artinya bahwa usahatani kakao menguntungkan dan layak untuk diusahakan karena nilai $\mathrm{R} / \mathrm{C}$ ratio $>1$.
\end{abstract}

Kata kunci: pendapatan, usahatani, kakao

\begin{abstract}
This study aims to: (1) calculate the amount of cocoa farm income, and (2) analyze the cocoa farm income in Pidie Jaya District of Aceh Province.This research was conducted by survey method. The research location is determined by the way (purposive) that Pidie Jaya district. Location of research include seven (7) districts, namely Bandar Baru, Bandar Dua, Trienggadeng, Meureudu, Meurah Dua, Ulim, and Panteraja. Site selection is done on the basis that each of these districts is a cocoa-producing regions. The population in this study were all cocoa farmers in Pidie Jaya District of Aceh Province. Sampling was done by farmers' simple random sampling method that randomly capture. The number of samples in this study were 101 respondents from the overall location of districts in Pidie Jaya district. Results showed that the cocoa farm income per hectare per district in Pidie Jaya Rp 14.4 million, -. Analysis of the cocoa farm income indicated by the value of $\mathrm{R} / \mathrm{C}$ ratio of 1.66 means that cocoa farming is profitable and worth the effort because the value of the $\mathrm{R} / \mathrm{C}$ ratio $>1$.
\end{abstract}

Keywords: income, farming, cocoa

\section{Pendahuluan}

Pembangunan pertanian yang berorintasi agribisnis melakukan salah satu pendekatan dengan pengembangan sistem agribisnis dan agroindustri yang di fokuskan pada pengembangan komoditas yang memiliki potensi untuk dikembangkan menjadi komoditi unggulan pada setiap daerah baik dari aspek sumberdaya alam maupun sumberdaya manusia sebagai stake- 
holder dalam pembangunan pertanian. Beberapa komoditi unggulan perkebunan rakyat berdasarkan wilayah di Propinsi Aceh dapat di lihat pada Tabel 1.

Akan tetapi di sisi lain terlihat bahwa selama ini keberadaan komoditi unggulan di berbagai wilayah di Propinsi Aceh belum mampu melepaskan daerah tersebut dari belenggu kemiskinan, misalnya Kabupaten Aceh Utara mendapatkan peringkat 1 (satu) kantong masyarakat miskin Propinsi Aceh. Kondisi yang tidak jauh berbeda juga di alami oleh kabupaten baru pemekaran dari Kabupaten Pidie yaitu Pidie Jaya yang jumlah penduduknya 142.811 jiwa dengan jumlah Kepala Keluarga 37.064 KK. Dengan mata pencaharian sebagai petani sejumlah 83 . 544 jiwa (58,5\%), nelayan 3.284 jiwa $(2,3 \%)$, PNS 3.236 jiwa $(1,8 \%)$, dan lain-lain 52.656 jiwa (37,9\%). Dari jumlah penduduk tersebut yang masih berada dalam kategori miskin sebanyak 4.102 KK atau 20.508 jiwa (Anonimous, 2009). Kondisi inilah akhirnya berpengaruh terhadap rendahnya produktivitas dan kemampuan petani Kakao dalam budidaya Kakao untuk meningkatkan kesejah-teraannya (Bappeda NAD, 2008).

Tabel 1. Komoditi Unggulan Perkebunan Rakyat berdasarkan Kabupaten dalam Wilayah Propinsi Aceh

\begin{tabular}{llll}
\hline No & Komoditi Perkebunan Rakyat & Kabupaten & Keterangan \\
\hline 1 & Kakoa & Pidie / Pidie Jaya & Kabupaten Pidie Jaya \\
2 & Kelapa Sawit & A. Utara/A.Timur/ A.Singkil & merupakan kabupaten \\
3 & Pinang & Bireun / A. Utara & baru pemekaran dari \\
4 & Kopi & Aceh Tengah/ Biner Meriah & Kabupaten Pidie. \\
5 & Kemiri & Gayo lues/ A. Tenggara & \\
\hline
\end{tabular}

Sumber: Bappeda NAD, 2007

Tabel 2. Luas Tanam dan Produksi Kakao Perkebunan Rakyat Menurut Kabupaten/Kota di Propinsi Aceh tahun 2007

\begin{tabular}{lcc}
\hline \multirow{2}{*}{ Kabupaten/Kota } & & 2007 \\
\cline { 2 - 3 } & Luas/Areal (ha) & Produksi (ton) \\
\hline Simeulue & 727 & 91 \\
Aceh singkil & 444 & 74 \\
Aceh selatan & 194 & 28 \\
Aceh Tenggara & 5.764 & 3.503 \\
Aceh Timur & 3.839 & 1.578 \\
Aceh Tengah & 109 & 4 \\
Aceh Barat & 367 & 45 \\
Aceh Besar & 684 & 182 \\
Pidie & 9.230 & 3.941 \\
Bireun & 2.845 & 1.998 \\
Aceh utara & 2.532 & 1.179 \\
Aceh Barat Daya & 1.404 & 345 \\
Gayo Lues & 407 & 20 \\
Aceh Tamiang & 976 & 358 \\
Nagan Raya & 2.698 & 569 \\
Aceh Jaya & 847 & 106 \\
Bener Meuriah & 174 & 10 \\
Banda Aceh & 0 & 0 \\
Sabang & 638 & 231 \\
Langsa & 225 & 150 \\
Lhokseumawe & 124 & 42 \\
Jumlah total & 34.228 & 14.454 \\
\hline
\end{tabular}

Sumber: Dinas Perkebunan dan Kehutanan Provinsi NAD, 2007. 
Perkembangan tanaman kakao (Theobroma Cacao, L) kakao dewasa ini ditinjau dari penambahan areal sungguh sangat memuaskan terutama perkebunan kakao rakyat dan perkebunan swasta. Kakao merupakan salah satu komoditi ekspor non migas yang memiliki prospek cukup cerah sebab permintaaan di dalam negeri semakin meningkat seiring dengan perkembangan sektor pertanian. Tanaman kakao merupakan tanaman perkebunan yang dinilai cukup prospektif untuk dikembangkan dan yang sudah dibudidayakan oleh sebagian petani sejak beberapa belas tahun yang lalu. Tabel 2 berikut memperlihatkan data luas tanam dan produksi kakao perkebunan rakyat menurut kabupaten/ kota di Propinsi Aceh. Di sisi lain, pemerintah Nanggroe Aceh Darussalam telah mengalokasikan dana sebesar Rp 141 miliar, untuk pembiayaan kepada petani miskin, penguatan lembaga perkebunan dan peningkatan Sumber Daya Manusia (SDM). Bila dibandingkan tahun 2007 lalu, alokasi anggaran APBD untuk perkebunan meningkat tajam yaitu mencapai $130 \%$. (Anonimous, 2008).

Usaha dan kebijakan tersebut akan dapat terealisasi apabila budidaya kakao dilakukan dengan benar sehingga produksi kakao dapat ditingkatkan. Petani kakao dalam hal ini tidak hanya berkepentingan dalam meningkatkan produksi kakao, akan tetapi yang lebih penting daripada itu adalah bagaimana dari peningkatan produksi kakao tersebut dapat meningkatkan pendapatannya dengan harapan kesejahteraan petani dapat lebih meningkat. Untuk mencapai tujuan tersebut maka penggunaan faktor-faktor produksi haruslah diusahakan dengan seefisien mungkin, karena semakin efisien petani melakukan usahatani, semakin efisien pula alokasi pembiayaan yang dikeluarkan.

Adapun yang menjadi tujuan penelitian ini adalah sebagai berikut:

1. Menghitung besarnya pendapatan usahatani kakao.

2. Menganalisis pendapatan usahatani kakao.

\section{Metode Penelitian}

Penelitian ini dilakukan dengan metode survey. Lokasi penelitian ditentukan dengan cara sengaja (purposive) yaitu Kabupaten Pidie Jaya. Lokasi penelitian meliputi tujuh kecamatan, yaitu Bandar Baru, Bandar Dua, Trienggadeng, Meureudu, Meurah Dua, Ulim, dan Panteraja,. Pemilihan lokasi ini dilakukan atas dasar bahwa masing-masing kecamatan tersebut merupakan daerah penghasil komoditi kakao. Data yang diperlukan dalam penelitian ini dapat dikelompokkan atas dua jenis yakni data primer dan data sekunder. Pengambilan data primer terhadap petani sampel dengan metode wawancara dengan mengunakan pertanyaan tersruktur dan sistematis (kuisioner) yang telah disusun sebelumnya serta observasi langsung. Data sekunder di kumpulkan dari dokumentasi pada berbagai instansi terkait meliputi Bappeda NAD, Bappeda Kabupaten, BPS Kabupaten, Dinas Pertanian, Dinas Perkebunan dan Kehutanan Kabupaten, Dinas Kantor Statistik Kecamatan, Asosiasi Petani Kakao dan berbagai sumber data resmi lainnya.

Populasi pada penelitian ini adalah semua petani kakao yang ada di Kabupaten Pidie Jaya Provinsi Aceh. Pengambilan sampel petani dilakukan dengan metode simple random sampling yakni pengambilan secara acak sederhana. Jumlah sampel dalam penelitian ini sebanyak 101 responden yang berasal dari lokasi keseluruhan kecamatan yang ada di Kabupaten Pidie Jaya.

Analisis data yang digunakan dalam penelitian ini adalah sebagai berikut.

1. Menghitung besarnya pendapatan usahatani kakao

Untuk menghitung besarnya pendapatan usahatani kakao digunakan rumus sebagai berikut. (Arsyad, 2000)

$$
\mathrm{TR}=\mathrm{P} \times \mathrm{Q}
$$

Keterangan:

$\mathrm{TR}=$ Total revenue (pendapatan)

$\mathrm{P}=$ Price (harga produk)

$\mathrm{Q}=$ Quantity (jumlah produk)

Untuk menghitung pendapatan bersih (keuntungan) yaitu dengan menggunakan formula sebagai berikut.

$$
\Pi=\mathrm{TR}-\mathrm{TC}
$$

Keterangan: $\Pi=$ Profit (keuntungan)

$\mathrm{TR}=$ Total revenue (pendapatan)

$\mathrm{TC}=$ Total cost (biaya total)

Biaya merupakan seluruh biaya yang dikeluarkan selama melakukan kegiatan usahatani yang meliputi biaya tetap dan biaya variabel.

$$
\mathrm{TC}=\mathrm{FC}+\mathrm{VC}
$$

Keterangan:

$$
\begin{aligned}
& \mathrm{TC}=\text { Total cost }(\text { biaya total }) \\
& \mathrm{FC}=\text { Fixed cost (biaya tetap) } \\
& \mathrm{VC}=\text { Variable cost (biaya variabel) }
\end{aligned}
$$


2. Menganalisis pendapatan usahatani kakao

Untuk menganalisis pendapatan usahatani kakao digunakan analisis $\mathrm{R} / \mathrm{C}$ ratio (Revenue Cost) ratio, yaitu dengan menghitung perbandingan antara pendapatan dengan biaya total yang dikeluarkan. Formulanya sebagai berikut. (Soekartawi, 1995)

$\mathrm{R} / \mathrm{C}$ ratio $=\underline{\text { Pendapatan }}$

$$
\text { Total Biaya }
$$

Kriteria keputusan sebagai berikut.

1. Bila $\mathrm{R} / \mathrm{C}$ lebih besar dari $1(\mathrm{R} / \mathrm{C}>1)$, artinya menguntungkan, layak diusahakan.

2. Bila $\mathrm{R} / \mathrm{C}$ sama dengan $1(\mathrm{R} / \mathrm{C}=1)$, artinya balik modal (BEP/Break Event Point).

3. Bila $\mathrm{R} / \mathrm{C}$ lebih kecil dari $1(\mathrm{R} / \mathrm{C}<1)$, artinya belum menguntungkan, tidak layak diusahakan.

\section{Hasil dan Pembahasan}

Data yang dikumpulkan dalam penelitian ini di analisis dan hasilnya di interprestasikan untuk mencapai tujuan penelitian.

\section{Produksi dan Produktivitas Kakao}

Produksi rata-rata kakao yang diperoleh $511.831,71 \mathrm{~kg}$ atau dengan rerata produktivitas (areal produktif) sebesar $534,82 \mathrm{~kg} / \mathrm{ha}$ per tahun. Tingkat produktivitas tersebut lebih tinggi apabila dibandingkan dengan rata-rata produktivitas kakao nasional yakni $515 \mathrm{~kg} / \mathrm{ha}$. Jumlah produksi dan produktivitas per kecamatan tertera pada Tabel 3 berikut.

Tabel 3. Jumlah Produksi dan Produktivitas Usaha tani Kakao per Kecamatan

\begin{tabular}{lrr}
\hline Kecamatan & Produksi (kg) & $\begin{array}{c}\text { Produktivitas } \\
(\mathrm{kg} / \mathrm{ha})\end{array}$ \\
\hline Bandar Baru & 221.390 & 768,72 \\
Bandar Dua & 2.109 .600 & 757,76 \\
Trienggadeng & 450.135 & 417,18 \\
Meureudu & 244.900 & 409,53 \\
Meurah Dua & 27.899 & 557,98 \\
Ulim & 220.998 & 471,21 \\
Pante Raja & 307.900 & 361,38 \\
\hline Jumlah & 3.582 .822 & $3.743,76$ \\
\hline Rata-rata & $511.831,71$ & 534,82 \\
\hline
\end{tabular}

Sumber: Data Diolah, 2011

Pendapatan Usahatani Kakao
Pendapatan merupakan tujuan akhir dari usahatani dan merupakan salah satu faktor yang sangat penting untuk menentukan tingkat kesejahteraannya. Besar kecilnya nilai hasil produksi yang diperoleh petani dari usahataninya sangat dipengaruhi oleh tinggi rendahnya hasil produksi dan didukung oleh tingkat harga produksi tersebut. Pendapatan bersih (keuntungan) usahatani kakao merupakan selisih nilai hasil produksi dengan total biaya produksi. Adapun rata-rata produksi dan didukung oleh tingkat harga produksi usahatani kakao di daerah penelitian dapat dilihat pada Tabel 4.

Tabel 4 memperlihatkan bahwa total biaya produksi yang dikeluarkan untuk tenaga kerja sebesar Rp 6.000.000,-. Tenaga kerja tersebut untuk kegiatan budidaya usahatani kakao meliputi kegiatan penyiangan/pemangkasa, pemupukan, pengendalian hama penyakit, panen, dan lain-lain.

Tabel 4. Pendapatan Usahatani Kakao per Kecamatan per Hektar

\begin{tabular}{lll}
\hline No. & Uraian & Total $(\mathrm{Rp})$ \\
\hline 1. & Biaya produksi & \\
& a. Tenaga kerja & 6.000 .000 \\
& b. Bahan & 2.438 .500 \\
& c. Peralatan & 202.500 \\
& Total Biaya & 8.641 .000 \\
2. & Pendapatan & 14.400 .000 \\
\hline
\end{tabular}

Sumber: Data Diolah, 2011

Total biaya produksi untuk bahan sebesar Rp 2.438.500,-. Bahan yang dimaksud adalah pupuk yang digunakan petani responden dalam usahatani kakao yaitu jenis pupuk urea, SP 36, $\mathrm{KCl}$. Obat-obatan pengendalian hama penyakit digunakan jenis pestisida dan herbisida. Bahan lainnya adalah plastik dan karet.

Total biaya produksi untuk peralatan sebesar Rp 202.500,-. Peralatan yang digunakan untuk usahatani kakao adalah cangkul, garu, parang, pisau, keranjang buah kakao, dan alat penyarungan. Biaya lain-lain yaitu untuk biaya Pajak Bumi dan Bangunan sebesar Rp 50.000,-.

Total keseluruhan biaya usahatani kakao adalah sebesar Rp 8.641.000,-. Jumlah penerimaan sebesar Rp 14.400.000,-. Sehingga pendapatan bersih atau keuntungan usahatani kakao adalah sebesar Rp 5.759.000,-.

Produksi yang diterima petani masih dapat di tingkatkan lagi yaitu dengan pemanfaatan sarana produksi seperti bibit, pupuk, obat-obatan dan lain-lain secara lebih tepat sehingga produksi yang dihasilkan meningkat. Nilai jual kakao 
merupakan hal sangat penting artinya terhadap pendapatan petani kakao. Semakin tinggi nilai jual dari hasil produksi, maka akan semakin besar pula keuntungan yang diterima petani. Sebaliknya apabila nilai jual kakao turun maka akan merugikan petani karena akan dapat mengurangi keuntungan petani.

\section{Analisis Pendapatan Usahatani Kakao}

Analisis pendapatan usahatani kakao sebagai berikut.

$$
\begin{aligned}
\mathrm{R} / \mathrm{C} \text { ratio } & =\frac{\text { Pendapatan }}{\text { Total Biaya }} \\
& =\operatorname{Rp} 14.400 .000,- \\
& =\operatorname{Rp} 8.641 .000,- \\
& =1,66
\end{aligned}
$$

Nilai R/C ratio sebesar 1,66 artinya bahwa usahatani kakao menguntungkan dan layak untuk diusahakan karena nilai $\mathrm{R} / \mathrm{C}$ ratio > 1 . Nilai $\mathrm{R} / \mathrm{C}$ ratio sebesar 1,66 menunjukkan bahwa dengan biaya sebesar Rp 8.641.000,- akan diperoleh penerimaan sebesar 1,66 kali lipat. Dengan kata lain, hasil penerimaan/pendapatan usahatani kakao mencapai $166 \%$ dari total biaya/modal yang dikeluarkan.

\section{Kesimpulan}

Total biaya usahatani kakao per hektar adalah sebesar Rp 8.641.000,-. Jumlah pendapatan usahatani kakao per hektar sebesar Rp 14.400.000,-. Analisis pendapatan usahatani kakao ditunjuk-kan oleh nilai $\mathrm{R} / \mathrm{C}$ ratio sebesar 1,66 artinya bahwa usahatani kakao menguntungkan dan layak untuk diusahakan karena nilai $\mathrm{R} / \mathrm{C}$ ratio $>1$.

\section{Saran}

Berdasarkan hasil penelitian, maka dapat direkomendasikan kepada petani kakao bahwa kegiatan usahatani kakao hendaknya dilakukan dengan baik guna meningkatkan produksi dan pendapatan usahatani kakao yang nantinya akan berdampak juga kepada peningkatan kesejahteraan petani kakao.

Perlu mendirikan suatu kawasan terminal agribisnis, dimana terminal agribisnis tersebut dapat menampung produksi yang dihasilkan oleh petani dengan harga yang sesuai, sehingga petani tidak dirugikan dengan pembelian kelapa sawit oleh pedagang pengumpul dengan harga yang murah.

\section{Daftar Pustaka}

Anonimous. 2008. Pidie Jaya dalam Angka, BPS Pidie Jaya, Meureudu

. 2008. Sekilas Kegiatan Aceh Partnerships for Economic Development (APED). Banda Aceh

Arifin B. 2005. Pembangunan Pertanian, Peradigma Kebijakan dan Strategi Revitalisasi, Grasindo, Jakarta.

Arsyad, Lincolin. 2002. Ekonomi Manajerial, Ekonomi Mikro Terapan untuk Manajemen Bisnis. Edisi ketiga. BPFE. Jakarta.

Bappeda NAD. 2008. Strategi dan Kebijakan pengembangan sektor perkebunan Propinsi Nanggroe Aceh Darussalam. Banda Aceh.

2007. Badan Perencanaan Pembangunan Daerah Propinsi Nanggroe Aceh Darussalam. Rencana Strategi pengembangan komoniti unggulan pertanian Nanggroe Aceh Darussalam. Banda Aceh 2008. Pidie Jaya dalam Angka, BPS Pidie Jaya, Meureudu

2005. Badan Perencanaan Pembangunan Daerah Propinsi Nanggroe Aceh Darussalam. Laporan Tahunan. Banda Aceh.

2005. Pusat Penelitian Kopi dan Kakao Indonesia.. Panduan Lengkap Budidaya Kakao. Agromedia Pustaka, Jakarta.

Rita Ariani. 2011. Model Efisiensi Alokatif Komoditi Kakao (Theobrema cacao L) Sebagai Upaya Peningkatan Produksi dan Pendapatan Petani di Provinsi Aceh, Laporan Penelitian, Fakultas Pertanian, Universitas Malikussaleh. Lhokseumawe.

Soekartawi. 1995. Analisis Usahatani. Universitas Indonesia. Jakarta. 